in, but resorts to bromide and iodide of potassium and kamela or turpentine given internally, to effect the complete cure. When spontaneous rupture of the cyst has occurred, he does not consider operative treatment desirable, unless constant discharge of blood or pus and cough are reducing the patient, when it must be treated as an abscess.

We must, however, leave further details of the methods of treatment, and many interesting cases in support of the views of the author, unnoticed. "Dr. Bird's monograph will well repay perusal, and we cannot but congratulate him on so valuable a contribution to medical science on an obscure and ill-recognised disease.

On the Pathology of the Pneumogastric Nerve. By S. O. Habershon, M.D., F.R.C.P., Senior Physician to, and Lecturer on Medicine at, Guy's Hospital, \&c. London : J. \& A. Churchill. 1877.

DR. HABERSHon has presented to the profession in this small work the lectures which he delivered last year as Lumleian Lecturer to the Royal College of Pbysicians. He flrst refers to the anatomical distribution and pbysiological action of the nerve, and then passes on to the various conditions in which this nerve is implicated, laying especial stress on its importance in connexion with the great functions of circulation, respiration, and digestion. The anatomy of the nerve is given very concisely but fully, although no mention is made of the auricular branch and the branches to the spleen, which have been traced by many observers, and are noticed in all standard anatomical works. The account of the physiological action of the nerve does not seem to us as complete as even a brief sum. mary should be, considering the precise character of the knowledge of the functions of this nerve which we now possess, as a result of numerous modern investigations. The physiological importance of the junction of the internal branch of the spinal accessory with the pneumogastric deserves more attention when room is found for an ingenious but very doubtful explanation of the reason why the superior laryngeal nerve supplies the crico-thyroid muscle. The pathology of the nerve is discussed under these three laws of action:-1. Disease at the origin of the nerve may induce symptoms in any of the peripheral branches, and this reflex state may be one of irritation and hyperæsthesia, or one of diminished power and anæsthesia; the one is spasmodic in character, the other paralytic. 2. Irritation in any set of peripheral muscles may produce disturbance in any other part to which the nerve is distributed, or in the centre itself. 3. Alternation of irritation may be induced, at first one set of nerves, then another, becoming im. plicated.

These laws are exemplified by various affections of the larynx, œsophagus, lungs, heart, and stomach, and some excellent cases in illustration of them are described. Dr. Habershon's remarks on the influence of the pneumogastric in the explanation of many of these conditions are very suggestive, although we fail to see the necessity for calling it to our aid in explaining some states which are easily ex. plicable on other and more widely-accepted grounds. It is hardly putting it fairly to say that in whooping-cough the mechanical pressure on the delicate air-cells may have to do with the production of emphysema, for this is surely a sufficient cause without the addition of a problematical factor, such as the influence of the pneumogastric. We had hoped that such a complex subject would have been treated at greater length, and that Dr. Habershon would have been able to find time to expand these lectures into a standard treatise. He would then have been able to lay greater stress on the more important phenomena, instead of presenting us with a mere bird's-eye view of most of the diseases of the organs to which the nerve is distributed. A table, containing twenty-four different conditions in which the stomach is implicated through the pneumogastric nerve, duly arranged as central, local, and peripheral, reminds us more of the student's examination knowledge than of the matured experience of so good a clinical observer as the author. We still hope that in a future edition these symptoms and phenomena will be more fully discussed, and our literature enriched by a work to which we may point as being exhaustive on a subject of so great interest and importance.

\section{EXCISION OF BRONCHOCELES.}

\section{To the Editor of The LaNCET.}

Sir,-I have read with much interest the case of excision of a bronchocele, by Professor Spence, of Edinburgh, in a girl of thirteen-firstly, because cases of suffocative goitre are comparatively rare; secondly, because a diffeult operation was evidently conducted with great skill and boldness; and, thirdly, because it is a question whether such operations ought ever to be undertaken. One can, however, only regret that the operation in question proved fatal, and that so speedily; though from the size of the tumour and its connexions, and the evident disturbanse of the vascular and sympathetic functions, the girl was far from being in a promising condition for a serious operation.

The results of these excisions do not appear to be favourable, and a surgeon might well hesitate to recommend or to undertake an operation involving parts of such great vascularity and vital importance as those in connexion with a bronchocele. I would suggest that in cases of dyspncea or dysphagia resulting from thyroid enlargement-which may be comparatively trifling in size - a more extended trial should be given to the use of the seton. I have several times seen cases of extreme dyspnca relieved within a few hours of the introduction of a large seton of two or more threads. The rules for the introduction of a seton are-that it should be a very large one; that it should be introduced very far back, almost touching the sterno-mastoids, and very deeply, almost touching the thyroid cartilage or trachea ; and that any large veins be pressed out of the way: the carotids can be fixed down behind the sterno-mastoids.

When suppuration is established, pull a larger seton through, and poultice freely; if the goitre is very large, injections of iodine may be made into its substance in various parts to assist in its resolution, but the seton is the sheet anchor, and after suppuration has commenced there is very little pain or distress.

I have had a man under my care whose life has been saved, certainly once, if not twice, by the seton, during the last eighteen months. On the first occasion he came to me suffering from intense paroxysms of dyspncea, produced by a small, hard bronchocele clasping the tracbea, and he stated that he had barely slept for a fortnight. After the intro. duction of a seton the dyspnoea entirely ceased. He retained the threads for a couple of months, when, as the goitre was much reduced and the breathing normal, I withdrew them. Some four months afterwards, be again presented himself at the hospital, terribly emaciated and feeble, stating that a fortnight previously the dyspnoa had returned, and that in addition he could literally swallow nothing, which was evident from his prostrate condition; he begged me to re introduce the seton, or do something to relieve him. i very large seton was now passed, and the next morning ie was able to eat a hearty breakfast. The seton was retained by his express wish for several months, and some difficlty has been experienced in reducing the exuberant gratulations from the seton-holes. He states, however, thit he would suffer anything rather than the suffocation and obstruction. The daughter of this patient is also urder my care for a similar swelling - showing its hereditary raturewhich has been nearly dispersed with a saturatd iodine tincture.

I would again strongly urge the use of lar'e setons, instead of the terrible alternative of excision, hich, even if successful, can hardly be called a triumph of argery. I am, Sir, your obedient sfvant,

Weymouth-street, W. LLEWELYN TPMAS, M, $D$. 